\title{
Correlation Between Income Level and Processes of Digitalization in Russian Federation
}

\author{
Shevyakin A.S. \\ South-West state university \\ Kursk, Russia \\ e-mail: andreas21074@mail.ru
}

\begin{abstract}
The article studies the indicators of income, in particular, the value of the subsistence minimum and the proportion of the population with incomes below this value. Attention is paid to the analysis of the population with incomes below average regional income. The regions with the largest share of the population with incomes below the subsistence minimum are identified. The author analyzes distribution of the population by the size of the ratio of income and the subsistence minimum in the different regions of the Russian Federation. In the article discusses the main factors of the low level of income and dynamics of the population of the Russian Federation with monetary incomes below the subsistence minimum. The substantiation of the important role of the level of differentiation of people's income for the processes of economical development and digitalization in the economy of the Russian Federation is given. The author concludes that low level of income is one of the factors of deterring of modern economy, because existing situation gives no stimulus for investing in the sphere of modern industrial sector and using of digital technologies in different sectors of economy especially in the regions of the country. The conclusion is made about the necessity of modernization of economy in order to increases the productivity of labor force in the regions of the country.
\end{abstract}

Keywords - labor resources, human resources, income, subsistence level.

\section{INTRODUCTION}

In the conditions of modern society and economy digitalization is one of the most important attributes of dynamic development. There are different approaches to analyzing of the intensity of the processes of digitalization. In our opinion, these processes first of all should be focused on improving the conditions for the formation and use of labor resources. This makes it relevant to compare the processes of digitalization of the regional economy with the dynamics of the living standards of the population.

Digitalization transform from an abstract concept to the real actions of different countries. Despite of that, there is still no comprehensive approach to assessing the progress of digitalization in a country, and existing studies either offer a macro-view at the world level, or are limited to a single industry or organization. Nevertheless, measuring of the progress of digitalization is the first necessary stage for the development of the process both for the country and for individual participants of the digital economy. One of the options for assessing this area can be the index "Digital Russia". At its calculation not only formalized quantitative indicators are used, but also other statistic information that must be taken into account at assessing the progress of digital economy. It is important, because the results of investigation may be used in different strategies, approaches and priorities of regions and participants of the economy.

\section{STATEMENT OF PROBLEM}

In a market economy human resources are considered from the position of a factor of production, acting as labor resources, first of all. The processes of formation and use of this kind of resources are multifaceted long-term process.

An important term for the qualitative expanded reproduction of human resources is to ensure a sufficiently high standard of living, which in the most part of cases is determined by the level of salary. The negative factor of influence to the labor force is poverty, that is, income that is insufficient to provide an acceptable standard of living for people.

\section{RESULTS AND DISCUSSION}

As a threshold value that determines the low level of wages, traditionally used the value of the subsistence minimum, which is a threshold value of the value sufficient to ensure the normal functioning of the individual. Figure 1 shows the dynamics of the subsistence minimum in the Russian Federation for the period 1992-2017.

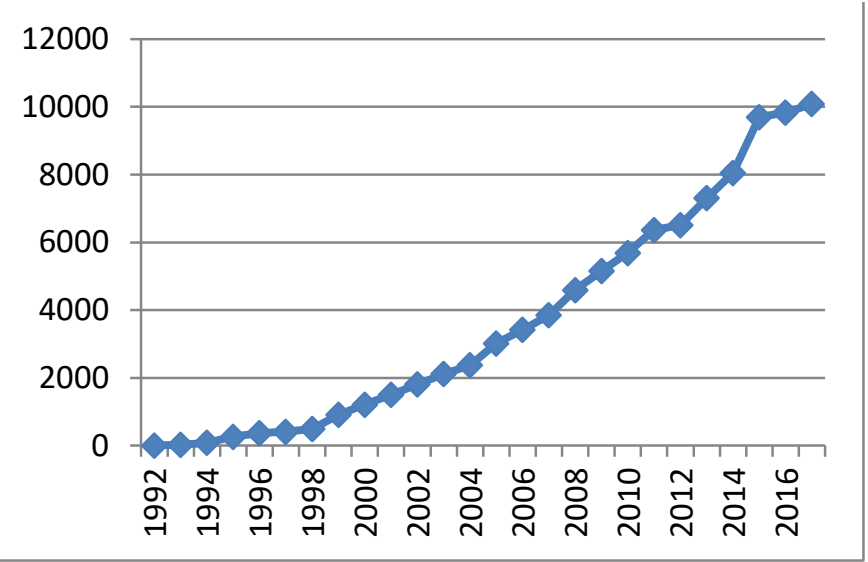

Fig. 1. Value of the subsistence minimum in the Russian Federation in 1992-2017

The analysis of the data presented in figure 1 shows a steady tendency to increase the value of the subsistence minimum for the study period. Until 2000 , there was a period of extremely intensive growth of this indicator, which was due 
to high inflation and crisis trends in the economy. Between 2000 and 2017, growth slowed to 8.3 times for this period. The largest increase of $20.5 \%$ was in 2015 and was manifested against the background of the economic crisis and sanctions from foreign policy pressure.

For a more complete analysis of the current situation, it seems relevant to study the population with personal income below the subsistence minimum and compare the values of the indicator for different regions of the Russian Federation in order to assess the level of their differentiation. The regions with the minimum share of the population with incomes below the subsistence minimum include the Moscow and Belgorod regions, the city of St. Petersburg and the Yamalo-Nenets Autonomous district. In these regions the level of this group of population does not exceed $10 \%$. The minimum value recorded in the Yamalo-Nenets Autonomous district at $7.5 \%$. In St. Petersburg and the Moscow region, the share of the population with per capita income below the subsistence level is only slightly higher: $8.1 \%$; and in the Belgorod region$7.9 \%$.

TABLE I. DISTRIBUTION OF THE POPULATION BY THE SIZE OF THE RATIO OF CASH INCOME AND THE SUBSISTENCE MINIMUM IN THE WHOLE OF THE RUSSIAN FEDERATION AND BY REGIONS IN 2017

\begin{tabular}{|l|l|l|l|l|l|l|l|l|}
\hline \multicolumn{1}{|c|}{ Region } & \multicolumn{7}{|c|}{ Interval groups of the ratio of cash } \\
income and the subsistence minimum \\
(SM)
\end{tabular}

The highest values of the indicator are observed in the Republic of Tyva, where there is a population with incomes below the subsistence minimum at a level above $40 \%$. In the Republic of Ingushetia, this indicator is $31.5 \%$, and in Kalmykia only slightly less than this value. It is possible to identify a sufficiently large number of depressed regions in this direction, in which the proportion of people with incomes below the subsistence minimum ranges from $18 \%$ to $25 \%$.

The analysis of the table 1 allows drawing a conclusion that in the Russian Federation the greatest share of the population in $26.4 \%$ falls on an interval group of monetary incomes from 3 to 6 sizes of subsistence minimum. A similar situation is observed in a number of regions that have high rates of economic development. However, in a number of regions, the largest part of the population falls on the interval groups with lower incomes. In particular, in the Republic of Crimea, $21.5 \%$ of the population receives income from 2 to 3 values of the subsistence minimum, and another $20.5 \%$ per interval group from 1 to 1.5 values. Similar situation is observed in the Chechen Republic.

It is advisable to analyze not only the population with incomes below the subsistence minimum, but also its distribution in relation to the average per capita income. This indicator allows making more complete study of the distribution of income and the degree of differentiation of the population by this indicator.

The studied data show that in the whole country this indicator ranges from 62 to $66 \%$. It can be noted as a positive trend in view of the rather low level of differentiation of incomes of the population in different regions of the Russian Federation. At the same time, a rather high proportion of the population, this has incomes below the average per capita, cause alarm. This group includes just a little under than twothirds of the total population.

The regions with the smallest population include the Tver region, the republics of Karelia and Ingushetia. In the Republic of Ingushetia, one of the highest percentages of the population with incomes below the subsistence minimum is observed in the country. In our opinion, the current trend can be explained by the low level of per capita income in the region. At the same time, in a number of regions with a relatively low proportion of the population with incomes below the subsistence minimum, on the contrary, there is the highest population with incomes below the per capita average. Such regions include Moscow and St. Petersburg, as well as the Yamalo-Nenets Autonomous district. Regions that have average rates for the proportion of population with incomes below the subsistence minimum are similarly represented in the middle of the list and for the population with incomes below the per capita average. This indicates about high degree of correlation of the studied indicators.

The analysis of the population with incomes below the subsistence minimum allows concluding that there are a number of negative factors of the insufficient level of financial wealth, which influence on the human resources of the region and the level of its development as a whole.

One of the most important factors of characterizing of the labor resources of the state is the level of wealth security of people, that is, income, which determine the standard of living and welfare. It is important to study not only the general average level, but also the degree of income differentiation of the population, as well as to pay special attention to the structure of the poor and the factors of its formation.

First of all, it is interesting to analyze the distribution of the general volume of accrued wages in the Russian Federation for five $20 \%$ groups of the population by income level. The diagram characterizing the changes in the structure of the distribution of the general volume of accrued wages in the period from 2005 to 2017 is presented in figure 2 .

During the study period, relatively small changes were observed in the structure of income distribution, which seems to be quite disproportionate, because the highest-paid group of the population receives for only slightly less than $50 \%$ of income. At the same time, both in 2005 and in 2017, this value remains almost unchanged. 


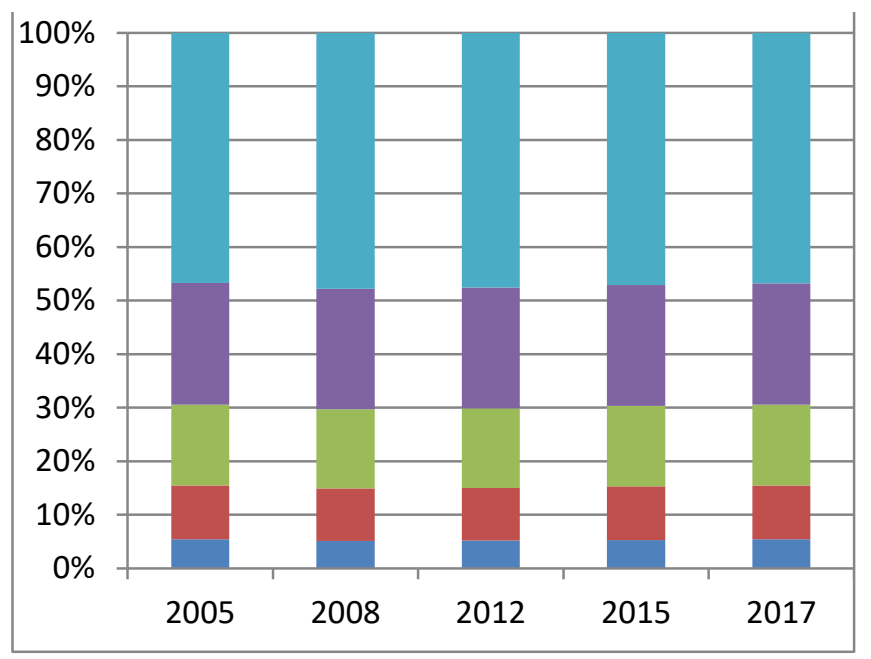

Fig. 2. The general volume of the salary in the Russian Federation in the period 2005 to 2017 , \%

The share of the least paid group after a slight decline in the period from 2005 to 2012 at the background of the crisis in the economy has increased again to $5.4 \%$ in 2017 . There is a negative trend, when the first four groups, that is, $80 \%$ of the population, receive about the same income as the $20 \%$ of the richest population. This disparity in income entails a number of negative consequences, determined by the stratification of society and the growth of social tension.

The high risks caused by the imbalance in the distribution of income, make it urgent to make an in-depth analysis of the income of the population on various indicators.

It seems interesting to compare the dynamics of the average accrued wages of workers in the Russian Federation by 20 percent groups. Figure 3 shows the graphs characterizing the dynamics of these indicators for the period from 2005 to 2017.

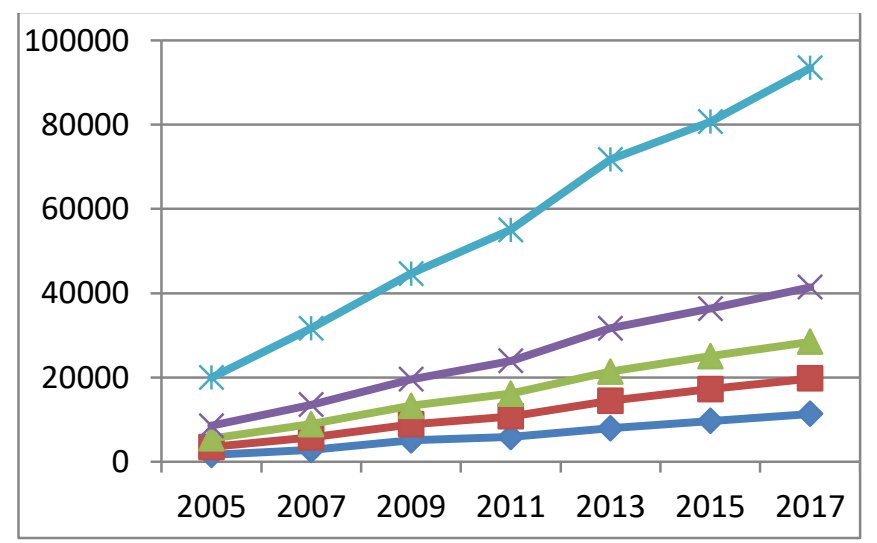

Fig. 3. Average accrued wages of employees in the Russian Federation for 20 percent groups in the period from 2005 to 2017

In the analysis of figure 3 , it can be noted that, despite the significant difference in income between the groups, the growth rates of income in the first group are the highest. During the study period, the average accrued salary of the first group increased by more than 6 times, and for the fifth group the growth was observed by about 4.5 times. This trend is positive, as it allows talking about a gradual leveling of the income level of the population. At the same time, the income differentiation of different groups of the population is still very large, and in absolute terms, the difference in income continues to increase. If in 2005 the average accrued salary for the first group was 1595 rubles, and for the fifth 19980 rubles, the difference was about 12.5 times in relative terms or 18385 rubles in absolute terms. In 2017, the average accrued salary for the first group was 11370 rubles, and for the fifth 93468 rubles. In relative terms, the wages of the fifth group were higher about 8.2 times, which suggests a reduction in the difference. At the same time, in absolute terms, the difference rose to 82098 rubles.

The analysis of the distribution of the total cash income of the population of the Russian Federation in 20 percent groups shows a persistent trend of reduction of the first group of the population with the lowest incomes to about $5 \%$ in 2017. This trend is typical for the second group. The third group of the population in terms of income is quite stable, as well as the fourth, for which there is only a slight increase. As a positive trend, we can highlight the gradual increase in the fifth group of the population with the highest incomes to almost half of the total structure.

The sharpest fluctuations in the structure of the population in terms of income were observed in the late 1980s and early 1990s. During this period there was a fairly sharp decline in the share of the fifth group with the highest incomes to less than $35 \%$, the second, third and fourth groups approximately maintained their size, and the first group with the lowest incomes significantly increased to almost $10 \%$ in 1990 . This trend is as a result of the economic crisis and the stagnation and further collapse of the USSR. The relative stability of the second, third and fourth groups were determined by the gradual transition of the population from the group with higher incomes to the group with lower. Given that the fall in income levels was observed nationwide, this mainly led to a decrease in the fifth group and an increase in the first. In all groups there was an active movement of the population, which was characterized by a significant decrease in the level of income in all 20 percent groups.

The author analyzed the distribution of the population at different levels of income. It showed that the largest population of the first group with a minimum income falls on the Volga Federal district, and in the relative structure of districts, this value is the largest in the North Caucasus Federal district. In the second group, the indicators of these Federal districts are quite close. For the three groups with the highest incomes, the leadership of the Central Federal district looks quite confident, since the fifth group with the highest incomes accounts for $46.8 \%$ of the total population of the Russian Federation with the highest incomes.

These trends, in our opinion, can be explained by disparity in income: higher income in the Central Federal district and especially in Moscow. This is confirmed by the fact that of the almost $40 \%$ of the population of the fifth group with the highest incomes in the Central Federal district $21.9 \%$ live in Moscow. $31.4 \%$ of the population of the Central Federal district lives in Moscow and more than $55 \%$ of the population from the fifth group with the highest incomes of 
the Central Federal district live in Moscow to. This thesis is confirmed by the analysis of the distribution of the 5 percent group of the population with the highest incomes. The Central Federal district accounts for $50.9 \%$ of the total population in this group, while Moscow accounts for $35.5 \%$, that is, approximately $70 \%$ of the population of the Central Federal district with the highest level of income. This fact indicates that the highest level of income of the population occurs in the Central Federal district and the most significant contribution to this trend is made directly by Moscow, whose incomes are the highest. In the capital of the Russian Federation the group of population with the highest incomes is also the largest. In our opinion, this is one of the most important factors of migration of the population, first of all, to Moscow and the Central Federal district as a whole.

Revealed facts make in-depth analysis of the income distribution of the population of the Russian Federation extremely relevant. In particular, it is interesting to compare the distribution of the incomes not only by geographical principle, but also by 20 percent groups of employees of organizations by type of economic activity for 2017. The analysis of this information gives us a chance to note the difference in the distribution of income in various sectors of the national economy. At the same time, there have been significant changes over the past few years. In General, there is a relative equalization of statistics, because 3-4 years ago, in some industries, the fifth group accounted for more than $60 \%$ of the employed. At present, the sectors of other services and activities in the field of culture and sports are significantly distinguished from others, in which the fifth group with the highest incomes accounts for significantly more than $50 \%$ of the employed. At the same time, the first two groups account for more than $10 \%$, and the first three groups-about $25 \%$ of workers. While for the vast majority of industries, the first two groups account for up to $20 \%$ of the employed, and the first three groups rarely account for less than $30 \%$.

It is possible to allocate branches in which there is a reverse tendency when on group with the greatest incomes it is account only slightly more than $40 \%$ of the employed. Such industries include, among others, education and health, as well as construction and manufacturing industries.

Figure 4 shows a graph, which characterizing the average income level of the population of the Russian Federation in the period from 2000 to 2017.

The analysis of the figure 4 help us to make a conclusion that the average income level of the population of the Russian Federation for the studied period increased more than 13 times from 2281 rubles in 2000 to 31477 rubles in 2017. At the same time, we must not forget about the inflationary impact. For this reason, it is most important to consider the growth of nominal incomes of the population in comparison with the dynamics of real incomes.

One more important indicator is dynamics of per capita income of the population of the regions of the Russian Federation. The lowest level of income for the entire period of the study is observed in the North Caucasus Federal district and is 22637 rubles per month in 2017. The highest level of income is observed in the Central Federal district: 40865 rubles per month in 2017, compared to 2009 , the increase was $86.3 \%$. During the study period, there is a positive dynamics of income growth, but against the background of the deterioration of the economic situation in 2015-2017 there is a drop in the growth rate and in some cases a decrease in the level of income, which was especially pronounced in the Eastern Federal district. For the period 2009-2017 in the Eastern Federal district, the increase was $80.3 \%$, and for the period 2009-2016, excluding the recession of 2017, this figure was $107.3 \%$. During the study period 2009-2017 the highest growth rate was recorded in the Southern Federal district $108.9 \%$, and the lowest in the Urals $-64.1 \%$.

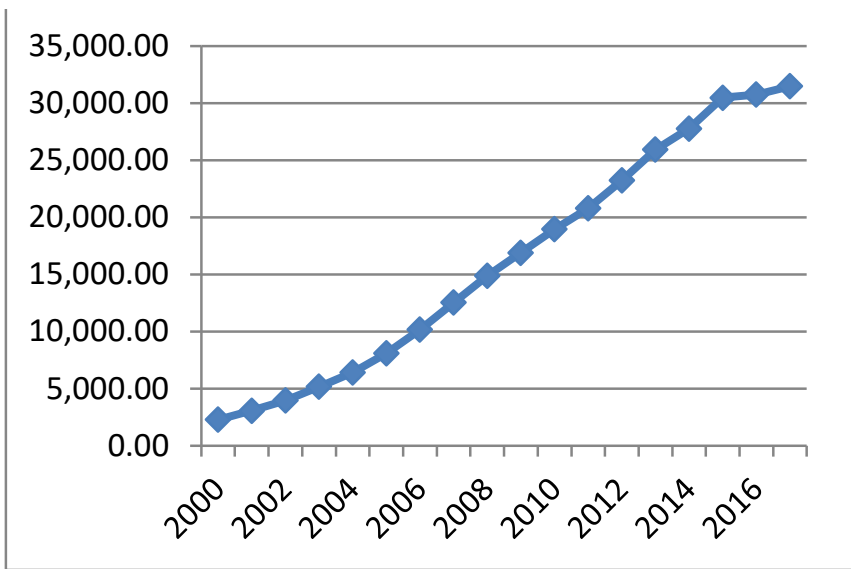

Fig. 4. Average income of the population of the Russian Federation in 20002017, rubles per month

\section{CONCLUSION}

It seems appropriate to consider and analyze the dynamics of the population of the Russian Federation with monetary incomes below the subsistence minimum. It is important to study not only the total population of this category of population, but the share of this population group in the total population of the Russian Federation. Figure 5 shows a graph describing the population of the Russian Federation in millions of people with monetary incomes below the subsistence minimum in the period from 1992 to 2017.

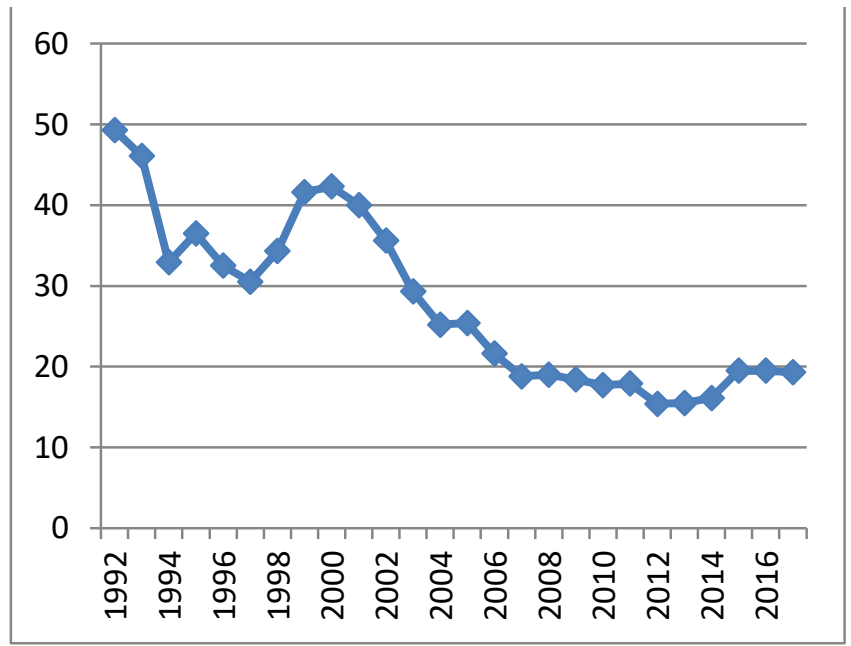

Fig. 5. Population of the Russian Federation with monetary incomes below the subsistence minimum in the period from 1992 to 2017 , million people 
The analysis of the figure 5 clearly shows the trend of dependence of the population with monetary incomes below the subsistence minimum on the economic situation in the country. The largest number of this population group was observed in 1992 and amounted to almost 50 million people. In the future, a significant increase in the studied indicator fell on the period 1998-2000, when it was a consequence of the economic crisis and default in the Russian Federation in 1998. Later there was a fairly stable tendency to reduce the population with monetary incomes below the subsistence minimum.

As a result, the number of this population group was reduced to 15.4 million people in 2012 under the influence of the complicated economic situation in the Russian Federation and the world economy, as well as against the background of sanctions pressure and slowing economic growth in recent years. The value of the studied indicator began to increase again. The growth was particularly intense in 2015, when the population of the Russian Federation with incomes below the subsistence minimum reached 19.5 million people. In 2016 and 2017 the population with monetary incomes below the subsistence minimum remained fairly stable, having slightly decreased in 2017 from 19.5 to 19.3 million people.

The important factor of the growth of the absolute population with monetary incomes below the subsistence minimum is the entry into the Russian Federation of the Peninsula of Crimea, due to which the population of the country as a whole has increased. This makes it relevant to analyze not only the total number, but also the share of this population group. Figure 6 shows a graph characterizing the share of the population with monetary incomes below the subsistence minimum in the Russian Federation in the period from 1992 to 2017

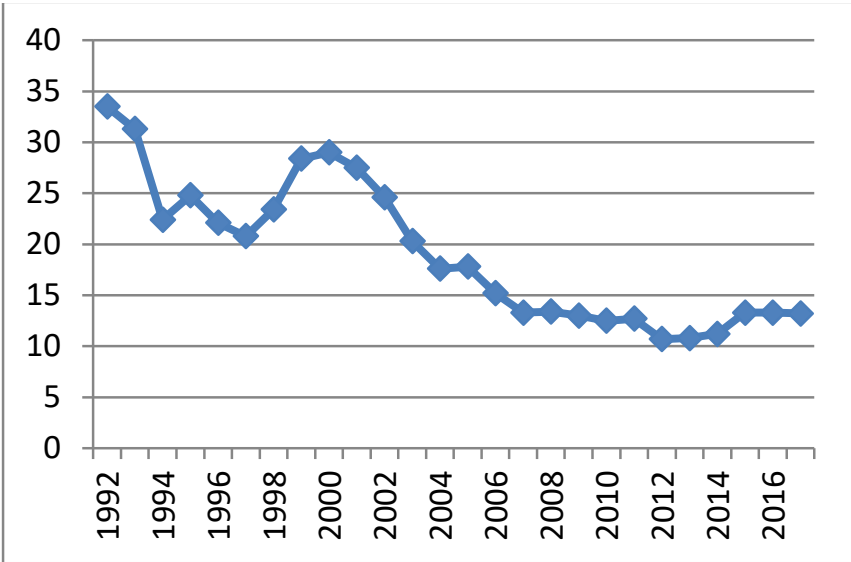

Fig. 6. Population of the Russian Federation with incomes below the subsistence minimum as a percentage of the total population in the period from 1992 to 2017 , \%
The graph of the share of the population with monetary incomes below the subsistence minimum largely correlates with the graph of the total number of this population group. This is due to the relatively high stability of the population of the country as a whole, which declined slowly during the study period.

In 1992 the study group accounted for $33.5 \%$ of the total population of the country, that is, a third part of the population lived with incomes below the subsistence level. In 1997 the share of this population group decreased to $20.8 \%$, but in 2000 it increased again to $29 \%$. The lowest value of the share of the population with monetary incomes below the subsistence minimum was observed in 2012, when it amounted to $10.7 \%$ of the total population of the Russian Federation. In the future, this value against the background of the negative economic situation in the country increased to $13.3 \%$ in 2015 , falling to $13.2 \%$ by 2017 .

The analysis shows that there is a high level of inconsistency between the indicators of digitalization of the economy and society as a whole and the standard of living of the population.

\section{References}

[1] I.V. Minakova, V.V. Kovarda, "Interchangeability and complementarity of resources in regional economy", Reg. econ.: theory and pract., no. 33 , pp. 2-9, 2011

[2] N.E. Tsukanova, "Demographic processes in Russia: current state and forecasting", National interests: priorities and security, no. 27, pp. 14-23, 2011.

[3] G.R. Baimurzina, F.I. Mirzabalaeva, "Efficiency Index of labor potential realization as an indicator of the quality of social and labor environment (regional aspect)", Probl. of territory development, vol. 2, no. 88, pp. 106-123, 2017.

[4] N.M. Rimashevskaya, V.K. Bochkareva, L.A. Mironova, E.V. Molchanova, M.S. Toksonbaeva, "Human potential of Russian regions", Population, vol. 6, no. 61, pp. 084-141, 2013.

[5] L.A. Migranova,, M.S. Toksanbaeva, "The Quality of labor potential of the Russian regions", Population, vol. 2, no. 64, pp. 102-120, 2014.

[6] A.S. Shevyakin, V.V. Kovarda, "Analyzes of labor resources of the Kursk region as a base of sustainable development of modern regional economy", The world of sci. openings, vol. 10-1, no. 22, pp. 549-559, 2011.

[7] A.S. Shevyakin, "Institutional factors of improving of the efficiency of the formation and use of labor resources in the regional economy", Manag. of econ. syst.: Electr. sci. J., vol. 12, no. 36, pp. 16, 2011.

[8] J.V. Narolina, T.V. Sabetova, N.V. Shabutskaya, N.V. Gryshchenko, "The influence of innovative development on economic security of the region", Proc. of the Voronezh State Univer. of Engineer. Technol., vol. 81, no. 1, pp. 457-463, 2019. Retrieved from: https://doi.org/10.20914/2310-1202-2019-1-457-463

[9] N.A. Serebryakova, I.V. Avdeev, "The content of structural transformations of the region's economy, adequate to the requirements of digitalization", Proc. of the Voronezh State Univer. of Engineer. Technol., vol. 80, no. 4, pp. 408-412, 2018. Retrieved from: https://doi.org/10.20914/2310-1202-2018-4-408-412 